\title{
In situ measurements of the direct-current conductivity of Antarctic sea ice: implications for airborne electromagnetic sounding of sea-ice thickness
}

\author{
J.E. REID, ${ }^{1}$ A. PFAFFLING, ${ }^{2}$ A.P. WORBY, ${ }^{3}$ J.R. BISHOP ${ }^{4}$ \\ ${ }^{1}$ School of Earth Sciences, University of Tasmania, Private Bag 79, Hobart, Tasmania 7001, Australia \\ E-mail: james.reid@utas.edu.au \\ ${ }^{2}$ Alfred Wegener Institute for Polar and Marine Research, PO Box 120161, D-27515 Bremerhaven, Germany \\ ${ }^{3}$ Antarctic Climate and Ecosystems Cooperative Research Centre and Australian Antarctic Division, Private Bag 80, Hobart, \\ Tasmania 7001, Australia \\ ${ }^{4}$ Mitre Geophysics Pty Ltd, PO Box 974, Sandy Bay, Tasmania 7006, Australia
}

\begin{abstract}
Airborne, ship-borne and surface low-frequency electromagnetic (EM) methods have become widely applied to measure sea-ice thickness. EM responses measured over sea ice depend mainly on the sea-water conductivity and on the height of the sensor above the sea-ice-sea-water interface, but may be sensitive to the sea-ice conductivity at high excitation frequencies. We have conducted in situ measurements of direct-current conductivity of sea ice using standard geophysical geoelectrical methods. Sea-ice thickness estimated from the geoelectrical sounding data was found to be consistently underestimated due to the pronounced vertical-to-horizontal conductivity anisotropy present in level sea ice. At five sites, it was possible to determine the approximate horizontal and vertical conductivities from the sounding data. The average horizontal conductivity was found to be $0.017 \mathrm{~S} \mathrm{~m}^{-1}$, and that in the vertical direction to be 9-12 times higher. EM measurements over level sea ice are sensitive only to the horizontal conductivity. Numerical modelling has shown that the assumption of zero sea-ice conductivity in interpretation of airborne EM data results in a negligible error in interpreted thickness for typical level Antarctic sea ice.
\end{abstract}

\section{INTRODUCTION}

Low-frequency geophysical airborne electromagnetic (EM) methods have become an important technique for remotely estimating sea-ice thickness. Airborne EM methods have been used extensively in the Arctic (Kovacs and others, 1987; Kovacs and Holladay, 1990; Liu and Becker, 1990; Haas and others, 2002; Prinsenberg and others, 2002), and surveys have recently also been conducted in Antarctica (Pfaffling and others, 2004). Airborne EM methods provide reliable estimates of the thickness of level sea ice: the Alfred Wegener Institute (AWI) helicopter EM (HEM-Bird) system considered in this study is able to determine modal thickness to within $10 \mathrm{~cm}$ for sea ice up to $3 \mathrm{~m}$ thick. Sea-ice thickness may, however, be significantly over- or underestimated in areas of deformed sea ice (e.g. pressure ridges), both as a result of the relatively poor lateral resolution of lowfrequency EM methods (e.g. Kovacs and others, 1995), and because data are routinely interpreted using simple, rapid 'layered-earth' interpretation algorithms.

Low-frequency EM techniques for measuring sea-ice thickness rely on the fact that the electrical conductivity of sea ice is typically one to two orders of magnitude smaller than that of polar sea water. The EM transmitter therefore mainly induces eddy currents in the conductive sea water, and secondary magnetic fields measured at the EM receiver depend mainly on the altitude of the EM system above the sea-ice-sea-water interface, and on the sea-water conductivity. Sea-ice thickness (or snow plus sea-ice thickness) is determined by subtracting the height of the EM system above the surface of the sea ice or snow, measured using a laser altimeter, from the depth to sea water estimated from the EM data. EM systems employed for sea-ice thickness measurements utilize transmitter frequencies of a few hundred $\mathrm{Hz}$ to $200 \mathrm{kHz}$. In most interpretations of airborne EM sea-ice thickness data, it is assumed that the conductivity of the sea ice is so low that it has no influence on the measured responses (e.g. Pfaffling and others, 2004). However, at higher transmitter frequencies $(>50 \mathrm{kHz})$, the measured airborne EM response may also be affected by the finite conductivity of the sea ice. The possibility exists that, in addition to thickness, sea-ice conductivity can also be recovered from high-frequency airborne EM data. Sea-ice conductivity data could potentially be used to derive information on the bulk brine volume of sea ice, and hence to estimate its mechanical properties, as discussed by Kovacs (1996).

The ability of airborne EM methods to determine sea-ice conductivity depends on the conductivity and thickness of the sea ice, and on the noise levels of the EM system. In this study, we use in situ direct-current (d.c.) geoelectrical methods to characterize the electrical conductivity of East Antarctic pack ice, in order to constrain interpretation of airborne EM sea-ice thickness data acquired during September-October 2003 as part of the Antarctic Remote Ice Sensing Experiment (ARISE). Airborne EM data were acquired using the AWI HEM-Bird system (Haas and others, 2002; Pfaffling and others, 2004). Theoretical modelling has been conducted in order to investigate the possibility of recovering sea-ice conductivity from practical AWI HEM-Bird EM data.

\section{D.c. electrical conductivity of sea ice}

Sea ice is an inhomogeneous composite of pure ice, brine, air and, at low temperatures, precipitated salts. A number of authors have reported results of in situ conductivity (or 


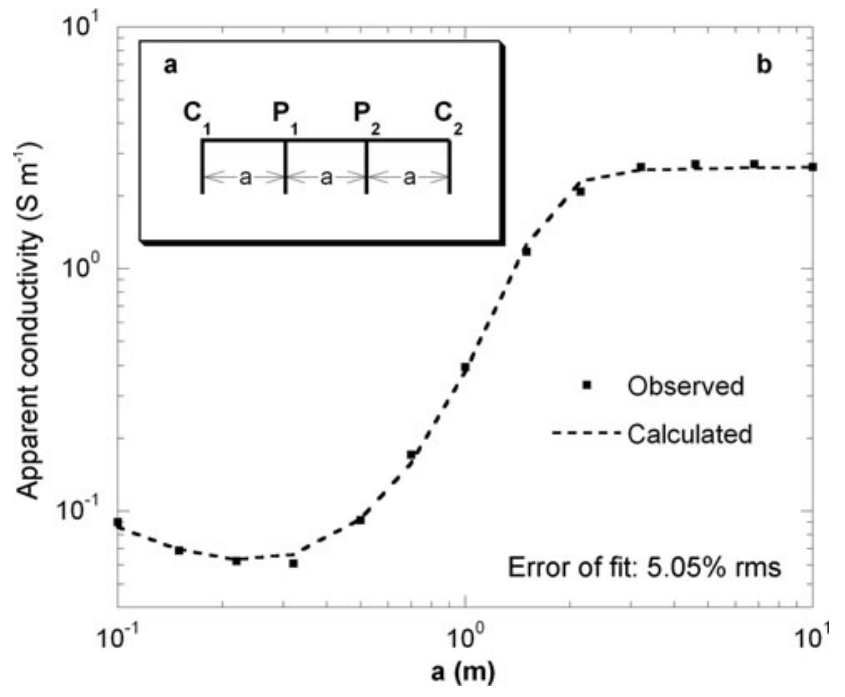

Fig. 1. (a) Wenner electrode array. Current $I$ is injected through current electrodes $C_{1}$ and $C_{2}$. The potential difference, $\Delta V$, resulting from the subsurface current flow is measured between potential electrodes $P_{1}$ and $P_{2}$. The ratio $\Delta V / I$ is the ground resistance $R$ in ohms. (b) Comparison of observed and calculated data for a typical Wenner-array geoelectrical sounding on sea ice (site 1b, Table 1). Resistances measured at each electrode spacing have been transformed to apparent conductivity, as described in the text. The calculated curve is the apparent-conductivity response of the best-fit three-layered model obtained by least-squares inversion of the observed data.

resistivity) measurements on Arctic and Antarctic sea ice. Thyssen and others (1974), Kohnen (1976), Timco (1979) and Buckley and others (1986) report results of traditional d.c. resistivity measurements on sea ice. Morey and others (1984) conducted time-domain reflectometry (TDR) measurements using 'ladders' of transmission lines frozen into growing Arctic sea ice, from which they were able to determine the d.c. conductivity. Becker and others (1992) determined in situ sea-ice conductivity using high-frequency EM methods $(8-16 \mathrm{MHz})$ via measurements of the radiation resistance of a circular loop antenna placed on the surface of the ice.

Columnar sea ice exhibits a preferred fabric, with the orientation of the $c$ axes of the ice crystals predominantly horizontal, perpendicular to the direction of sea-ice growth (Timco, 1979; Weeks and Ackley, 1986). Brine inclusions within the sea ice occur as thread-like cells arranged in thin, vertically oriented layers. The shape of the brine cells is temperature-dependent: the cells are needle-shaped at low temperatures, but become disc-shaped at very warm temperatures (Timco, 1979). As the sea ice grows thicker, the entrapped brine drains out under gravity, forming vertically aligned drainage tubes. Drainage tube diameters are typically $0.1-1 \mathrm{~cm}$, although diameters of up to $10 \mathrm{~cm}$ have been reported (Weeks and Ackley, 1986). Under certain temperature conditions, the drainage tubes may extend through the entire thickness of the sea ice (Golden, 2001).

The vertical orientation of both the brine cells and drainage tubes imparts a strong conductivity anisotropy to the sea ice, with the bulk conductivity in the vertical direction being higher than that in the horizontal direction (Thyssen and others, 1974). Thyssen and others (1974) verified the presence of this conductivity anisotropy in situ, by making direct measurements of the horizontal and vertical conductivities in the walls of a pit excavated in thick, undeformed Arctic sea ice. Buckley and others (1986) detected a similar anisotropy in first-year Antarctic sea ice.

\section{RESULTS}

Direct-current measurements of sea-ice conductivity were made using a Wenner electrode array to conduct geoelectrical soundings (Fig. 1a). Sixteen measurements were made on first-year pack ice within the region bounded by latitudes $63^{\circ} 56.2^{\prime} \mathrm{S}$ and $65^{\circ} 14.3^{\prime} \mathrm{S}$ and longitudes $109^{\circ} 27.3^{\prime} \mathrm{E}$ and $117^{\circ} 44.5^{\prime} \mathrm{E}$. At each measurement site, the electrically insulating snow cover was removed, and resistance measurements were made at a series of electrode separations ranging from $a=0.1 \mathrm{~m}$ to $\mathrm{a}=10 \mathrm{~m}$ (Fig. 1a) with the midpoint of the array fixed in position. For the purposes of data interpretation, the measured resistances were then transformed to apparent resistivity $\left(\rho_{\mathrm{a}}\right)$ according to the equation

$$
\rho_{\mathrm{a}}=2 \pi \mathrm{aR},
$$

where $a$ is the electrode spacing $(\mathrm{m})$ and $R$ is the measured resistance $(\Omega)$.

The apparent-resistivity vs electrode-separation data were then interpreted assuming a one-dimensional (layered) model, in which conductivity was assumed to be isotropic and to vary only with depth. The layered conductivity model was obtained using an iterative least-squares inversion process, in which the parameters of a starting model were automatically adjusted until the apparent-resistivity curve computed for the model matched the field data. Figure $1 \mathrm{~b}$ shows a typical comparison of observed data (symbols) with the calculated response of the best-fit three-layered model (dashed line) obtained via one-dimensional (1-D) inversion. Note that observed and calculated data have been plotted as apparent conductivity $\left(\sigma_{\mathrm{a}}=1 / \rho_{\mathrm{a}}\right)$.

For the majority of the d.c. Wenner-array measurements, the interpreted three-layered model comprised a thin, conductive near-surface layer, a thicker, less conductive middle layer and a highly conductive lower layer (sea water). This conductivity distribution is typical of that for young (first-year) sea ice, and has been previously observed in both the Arctic (Thyssen and others, 1974) and Antarctic (Buckley and others, 1986). If the sea-ice conductivity were isotropic, the sum of the interpreted thicknesses of the upper two layers would yield the depth to sea water below the surface, i.e. sea-ice thickness. Figure 2 compares the sea-ice thicknesses determined from the d.c. geoelectrical sounding data with the actual thickness obtained by drilling. The thickness interpreted from the d.c. sounding data consistently underestimates the drilled thickness. This is mainly the result of the high vertical conductivity of the sea ice, in comparison to that in the horizontal direction (Maillet, 1947; Thyssen and others, 1974). Another factor which may contribute to underestimation of the thickness is where the depth to sea water below the electrode array is highly variable: this renders the assumed 1-D interpretation model invalid and may result in erroneous interpreted seaice thicknesses.

In addition to the d.c. soundings, 13 azimuthal d.c. conductivity measurements were carried out at the field sites using an offset Wenner array (Watson and Barker, 1999), in order to identify any anisotropy of conductivity in the horizontal plane. The offset Wenner array is a variant of the traditional Wenner array which enables the effect of 


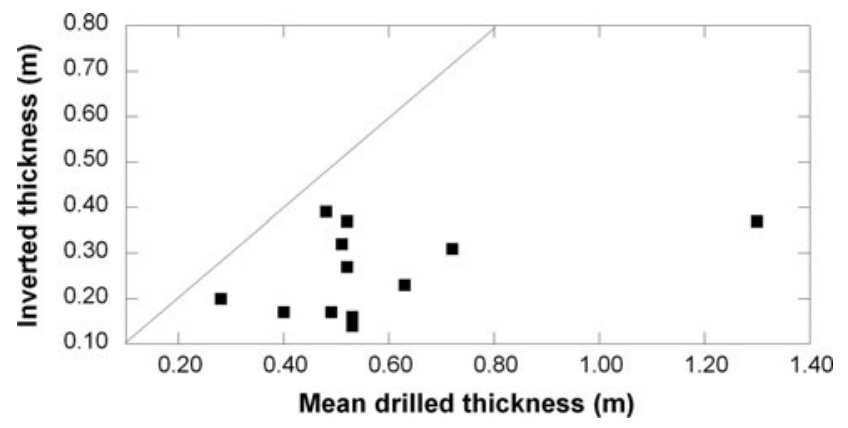

Fig. 2. Plot of sea-ice thickness interpreted from East Antarctic d.c. geoelectric soundings vs actual drilled thickness. Thicknesses were obtained from the d.c. sounding data via inversion of field data assuming a three-layered model, as described in the main text. The solid line indicates a 1:1 correspondence between interpreted and drilled thicknesses. The d.c. conductivity method consistently underestimates the actual sea-ice thickness mainly as a result of the pronounced vertical to horizontal conductivity anisotropy in undeformed sea ice.

azimuthal variations in conductivity resulting from anisotropy to be distinguished from those which arise due to other effects, such as changes in sea-ice thickness beneath the electrode array. Our offset Wenner data did not conclusively identify any anisotropy of conductivity in the horizontal plane. This result was expected, given that azimuthal conductivity variations develop as a result of a preferred horizontal orientation of the $c$ axes of the ice crystals, which can occur when sea ice forms in a fixed location relative to a prevailing current direction, such as for landfast ice (Weeks and Ackley, 1986). As noted by Weeks and Ackley (1986), the dynamic nature of the Antarctic ice pack means that floes are free to rotate during sea-ice growth, and that no preferred horizontal $c$-axis orientation can develop.

\section{Resolution of horizontal and vertical conductivities}

Our Wenner sounding and offset Wenner azimuthal data show that the sea-ice conductivity is horizontally isotropic, but that the vertical conductivity is higher than the horizontal conductivity. This type of electrical structure is referred to as 'transversely isotropic' in the geophysical literature. Maillet (1947) has shown that a transversely isotropic layer of thickness $t_{\mathrm{a}}$, with conductivities of $\sigma_{\mathrm{h}}$ and $\sigma_{\mathrm{v}}$ in the horizontal and vertical directions respectively, yields an identical d.c. sounding response to an isotropic layer of thickness $t=\left(\sigma_{\mathrm{h}} / \sigma_{\mathrm{v}}\right)^{1 / 2} t_{\mathrm{a}}$ and conductivity $\sigma_{\mathrm{m}}=$ $\left(\sigma_{\mathrm{h}} \sigma_{\mathrm{v}}\right)^{1 / 2}$. This equivalence is illustrated in Figure 3. The quantity $f=\left(\sigma_{\mathrm{h}} / \sigma_{\mathrm{v}}\right)^{1 / 2}=t / t_{\mathrm{a}}$ is the coefficient of anisotropy. In typical situations, it is not possible to identify the presence of this type of anisotropy on the basis of surface geoelectrical sounding data. In the sea-ice case, the difference between the interpreted thickness $(t)$ and drilled thickness $\left(t_{\mathrm{a}}\right)$ reveals the presence of the anisotropy: the ratio $t / t_{\mathrm{a}}$ allows us to directly determine $f$ and hence to resolve $\sigma_{\mathrm{h}}$ and $\sigma_{\mathrm{v}}$ independently, since

$$
f_{\mathrm{m}_{\mathrm{m}}}=\sqrt{\frac{\sigma_{\mathrm{h}}}{\sigma_{\mathrm{v}}}} \sqrt{\sigma_{\mathrm{h}} \sigma_{\mathrm{v}}}=\sigma_{\mathrm{h}} .
$$

$\sigma_{\mathrm{v}}$ is easily obtained once $\sigma_{\mathrm{h}}$ has been determined as above. Thyssen and others (1974) calculated horizontal and vertical conductivities using the same approach.
Anisotropic model

Air

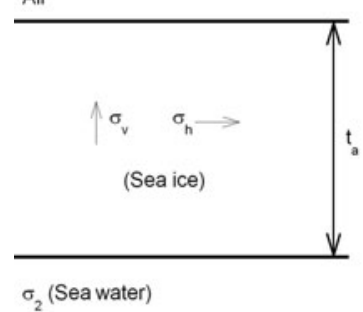

Equivalent isotropic model

Air

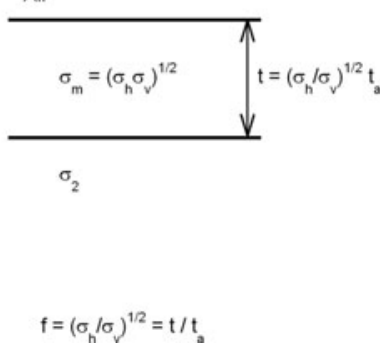

Fig. 3. Equivalent transversely isotropic (left) and isotropic (right) 1 -D d.c. geoelectrical models. For the anisotropic case, $\sigma_{\mathrm{v}}$ and $\sigma_{\mathrm{h}}$ are the conductivities in the vertical and horizontal directions respectively, and $t_{a}$ is the layer thickness. In the isotropic model, $\sigma_{\mathrm{m}}$ and $t$ are the equivalent upper-layer conductivity and thickness respectively. In both models, the conductivity of the bottom layer (sea water) is isotropic.

We have performed a detailed analysis of five of our geoelectrical soundings for which drilling revealed the seaice thickness to be essentially constant below the electrode array, and where our assumed 1-D interpretation model was appropriate. At the other field sites, drilled sea-ice thickness below the electrode array varied by tens of centimetres to metres, and it was not possible to assume that the underestimation of sea-ice thickness was solely due to conductivity anisotropy. For each of the soundings on level sea ice, an adequate fit to the observed data was obtained using a threelayered model containing a near-surface conductive layer (Thyssen and others, 1974; Buckley and others, 1986). The smallest electrode spacing used for the field measurements $(a=0.1 \mathrm{~m}$; Fig. 1a) was too large to allow the conductivity and thickness of the uppermost layer to be determined (Buckley and others, 1986). However, an equivalence analysis of the data indicates that the upper layer is at most a few centimetres thick. All of the equivalent models for the upper conductive layer have an identical longitudinal conductance (conductivity-thickness product); the calculated conductance of the layer, $S_{1}$, is given in Table 1 .

The small thickness of the upper conductive layer means that the sea-ice thickness interpreted from the geoelectrical sounding data is essentially equal to the thickness of the second layer of the model. Subject to this assumption, it is possible to calculate $f$ and hence to determine approximate horizontal and vertical conductivities for the second model layer, which represents the bulk of the sea ice. The results of these calculations are summarized in Table 1 and plotted in Figure 4.

The conductivities listed in Table 1 are consistent with those from other published in situ data. Thyssen and others (1974) measured horizontal and vertical conductivities in the wall of a pit excavated in Arctic sea ice, and obtained $\sigma_{\mathrm{h}}=0.01 \mathrm{~S} \mathrm{~m}^{-1}$ and $\sigma_{\mathrm{v}}=0.063 \mathrm{~S} \mathrm{~m}^{-1}$. Buckley and others (1986) noted the presence of conductivity anisotropy in Antarctic sea ice of thickness 1.35-1.75 m, but did not determine $\sigma_{\mathrm{h}}$ and $\sigma_{\mathrm{v}}$. Based on their published data, we have calculated values of $\sigma_{\mathrm{h}}$ between 0.002 and $0.01 \mathrm{~S} \mathrm{~m}^{-1}$ and $\sigma_{v}$ between 0.01 and $0.034 \mathrm{Sm}^{-1}$. The in situ TDR measurements of Morey and others (1984) measured horizontal conductivities for $1.4 \mathrm{~m}$ thick first-year Arctic 


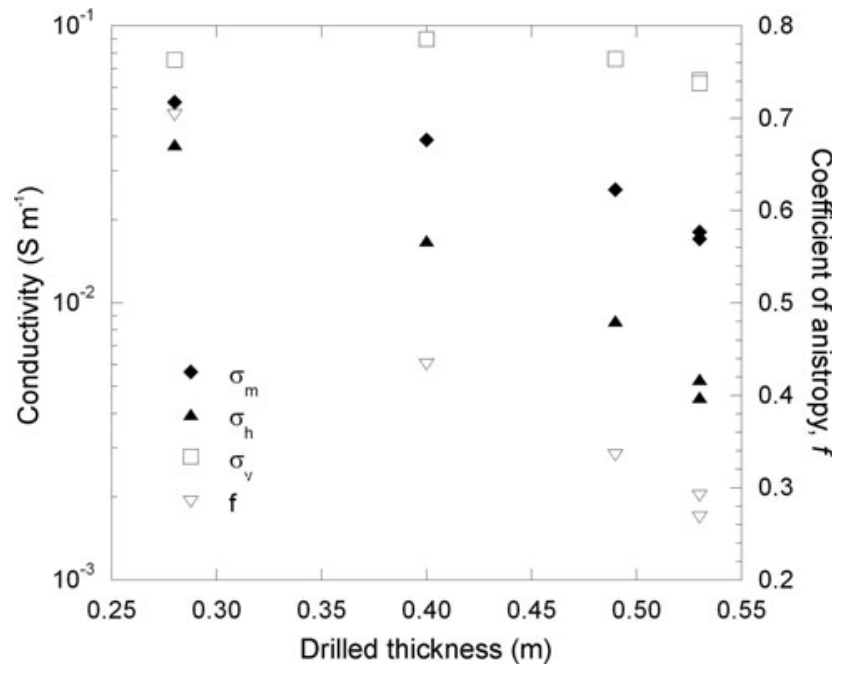

Fig. 4. Graph of in situ sea-ice conductivity and coefficient of anisotropy vs drilled thickness for five d.c. geoelectrical soundings on level sea ice in East Antarctica. $\sigma_{\mathrm{h}}$ and $\sigma_{\mathrm{v}}$ are the interpreted seaice conductivities in the horizontal and vertical directions respectively. $\sigma_{\mathrm{m}}$ is the conductivity of the equivalent isotropically conductive layer and is equal to the geometric mean of the horizontal and vertical conductivities.

sea ice of between $0.009 \mathrm{~S} \mathrm{~m}^{-1}$ near the top of the sea ice and $0.13 \mathrm{~S} \mathrm{~m}^{-1}$ near the more porous base. It should be noted that conductivities interpreted from d.c. geoelectrical data assign bulk horizontal and vertical conductivities to the sea ice and cannot be directly compared with the results of Morey and others (1984) which were made at a much smaller horizontal scale $(\sim 1 \mathrm{~cm})$ at a range of depths within the sea ice.

\section{Comparison with Archie's law}

In the absence of in situ data, a first approximation to the sea-ice conductivity can be estimated from core samples using the empirical Archie's law (Archie, 1942; Haas and others, 1997) which relates the bulk conductivity $\sigma$ of the sea ice to its porosity (assumed equivalent to the brine volume, $v_{\mathrm{b}}$ ) and the conductivity of the brine, $\sigma_{\mathrm{b}}$ :

$$
\sigma=\sigma_{\mathrm{b}}\left(v_{\mathrm{b}}\right)^{m} \text {. }
$$

Values for the constant $m$, appropriate to sea ice, have been determined by Thyssen and others (1974) and Morey and others (1984). Thyssen and others (1974) obtained $m=2.2$, while Morey and others (1984) obtained $m=1.55$ near the top of the sea ice, and 1.75 near the base. The change in the value of $m$ with depth was attributed to a change in structure of the sea ice from a vertical $c$-axis orientation near the top of the ice to a predominantly horizontal $c$-axis orientation near the base. Haas and others (1997), Worby and others (1999) and Tateyama and others (2004) all assumed a value of $m=1.75$ for their Archie's law calculations.

Calculation of $v_{\mathrm{b}}$ requires salinity and temperature measurements along the length of the core. The salinity measurement requires that the core sections be melted, which has the important consequence of destroying the structural fabric of the sea ice, and hence any anisotropy. The Archie's law conductivities can also be affected by loss of brine when the core is extracted from the sea ice.

We have calculated $v_{b}$ using the method of Cox and Weeks (1983). The brine conductivity $\sigma_{\mathrm{b}}$ for each core interval was calculated from the measured temperature using an equation given by Stogryn and Desargant (1985):

$$
\sigma_{\mathrm{b}}=-T \exp (0.5193+0.08755 T), \quad T \geq-22.9^{\circ} \mathrm{C},
$$

where $T$ is the temperature in degrees Celsius and $\sigma_{\mathrm{b}}$ is in $\mathrm{Sm}^{-1}$.

Figures 5 and 6 show salinity and temperature measurements for the cores from sites $1 \mathrm{a}$ and 2, as well as bulk conductivities determined using Archie's law for two published values of $m$. These cores correspond to the sites with the smallest (site 1a) and largest (site 2) coefficients of anisotropy determined from the Wenner d.c. soundings. Horizontal and vertical conductivities determined from the Wenner sounding data are indicated by the horizontal dashed lines in Figures $5 \mathrm{~b}$ and $6 \mathrm{~b}$. The Archie's law conductivities calculated for $m=1.75$ are generally a better approximation to $\sigma_{\mathrm{v}}$ than $\sigma_{\mathrm{h}}$. We have determined bulk core conductivities by summing the conductances (conductivity times length) of each core segment and dividing by the total length of the core. Assuming $m=1.75$, bulk conductivities calculated for cores $1 \mathrm{a}$ and 2 are 0.063 and $0.098 \mathrm{~S} \mathrm{~m}^{-1}$. For $m=2.2$, bulk conductivities are $0.023 \mathrm{~S} \mathrm{~m}^{-1}$ (core 1a) and $0.041 \mathrm{~S} \mathrm{~m}^{-1}$ (core 2).

The data shown in Table 1 indicate coefficients of anisotropy $(f)$ for East Antarctic pack ice of 0.27-0.7. Thyssen and others (1974) obtained $f=0.26$ for undeformed sea ice, and found deformed sea ice to be isotropic $(f=1)$ as a result of destruction of the preferred fabric in undeformed sea ice. Buckley and others (1986) obtained a

Table 1. Results of in situ d.c. conductivity measurements on level East Antarctic pack ice. Measurements were made during the period 26 September-20 October 2003. Temperature $(T)$ was measured at the snow-sea-ice interface; sea-water temperature was $\approx-1.8^{\circ} \mathrm{C}$. $t_{\mathrm{a}}$ is the mean drilled thickness of the sea ice. $t$ and $\sigma_{\mathrm{m}}$ are the sea-ice thickness and second-layer conductivity interpreted from d.c. geoelectrical data assuming a layered isotropic model, and $S_{1}$ is the conductance (conductivity-thickness product) of the first layer. $f$ is the coefficient of

\begin{tabular}{|c|c|c|c|c|c|c|c|c|c|c|}
\hline Site & $\begin{array}{l}\text { Lat. } \\
{ }^{\circ} \mathrm{S}\end{array}$ & $\begin{array}{l}\text { Long. } \\
{ }^{\circ} \mathrm{E}\end{array}$ & $\begin{array}{l}\mathrm{T} \\
{ }^{\circ} \mathrm{C}\end{array}$ & $\begin{array}{l}t_{\mathrm{a}} \\
\mathrm{m}\end{array}$ & $\begin{array}{c}t \\
\mathrm{~m}\end{array}$ & $\begin{array}{l}S_{1} \\
\mathrm{~S}\end{array}$ & $f$ & $\begin{array}{c}\sigma_{\mathrm{m}} \\
\mathrm{S} \mathrm{m}^{-1}\end{array}$ & $\begin{array}{c}\sigma_{\mathrm{h}} \\
\mathrm{S} \mathrm{m}^{-1}\end{array}$ & $\begin{array}{c}\sigma_{\mathrm{v}} \\
\mathrm{S} \mathrm{m}^{-1}\end{array}$ \\
\hline $1 \mathrm{a}$ & $-64^{\circ} 37.7^{\prime}$ & $117^{\circ} 44.5^{\prime}$ & -8.1 & 0.53 & 0.14 & 0.0065 & 0.27 & 0.0171 & 0.0046 & 0.0637 \\
\hline $1 b$ & $-64^{\circ} 37.7^{\prime}$ & $117^{\circ} 44.5^{\prime}$ & -8.4 & 0.49 & 0.17 & 0.0082 & 0.35 & 0.0256 & 0.0090 & 0.0729 \\
\hline $1 \mathrm{c}$ & $-64^{\circ} 37.7^{\prime}$ & $117^{\circ} 44.5^{\prime}$ & - & 0.53 & 0.16 & 0.0084 & 0.29 & 0.0180 & 0.0053 & 0.0613 \\
\hline 2 & $-64^{\circ} 36.7^{\prime}$ & $116^{\circ} 43.7^{\prime}$ & -3.6 & 0.28 & 0.20 & 0.0035 & 0.70 & 0.0530 & 0.0373 & 0.0753 \\
\hline
\end{tabular}
anisotropy, and $\sigma_{\mathrm{h}}$ and $\sigma_{\mathrm{v}}$ are the approximate horizontal and vertical conductivities, calculated as described in the text 

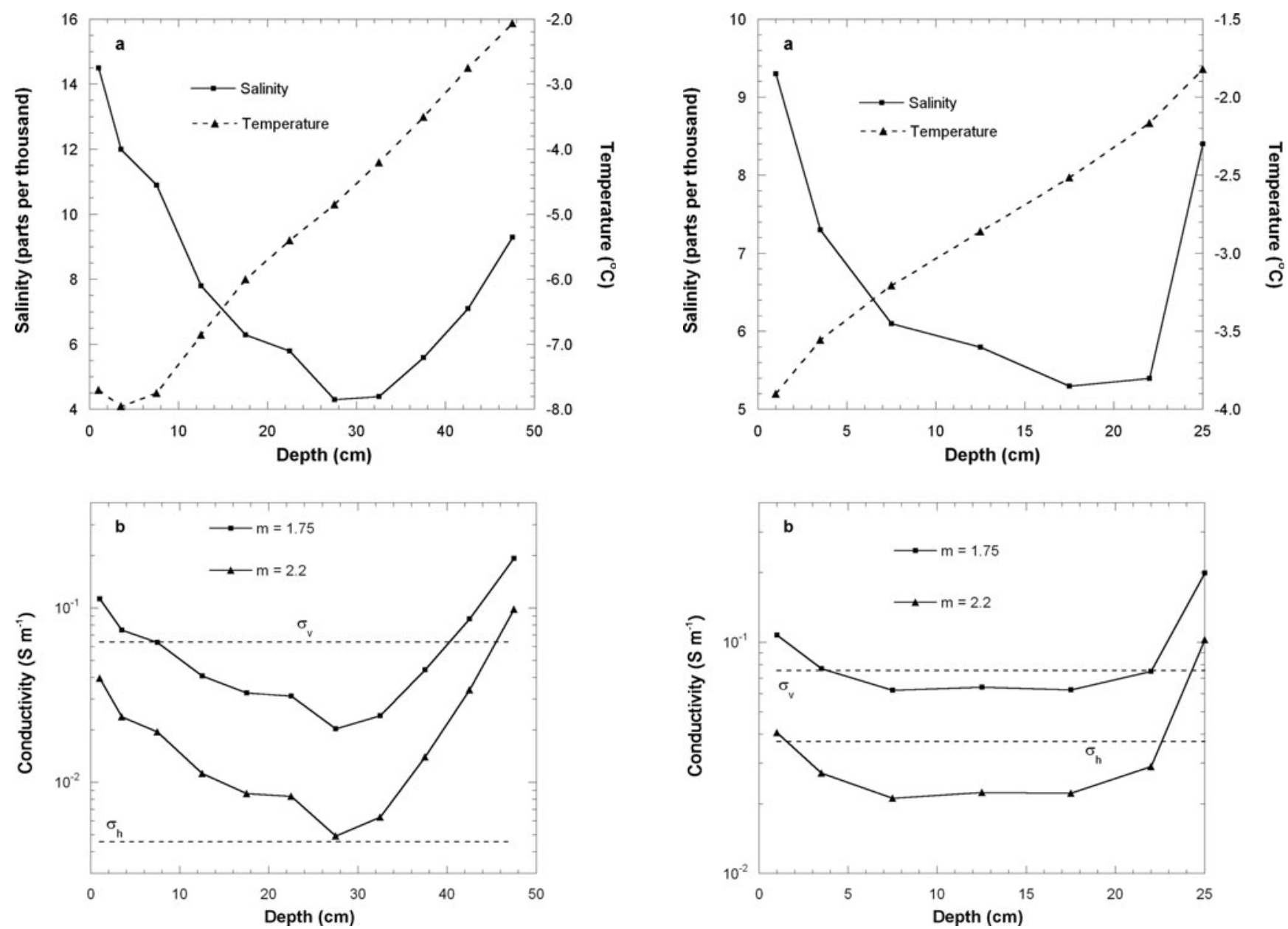

Fig. 5. (a) Salinity and temperature profiles measured on a sea-ice core from site 1a (Table 1). (b) Bulk sea-ice conductivity computed from the data in (a) using Archie's law, for different values of the exponent $m$. The horizontal dashed lines denote the horizontal $\left(\sigma_{\mathrm{h}}\right)$ and vertical $\left(\sigma_{v}\right)$ conductivities determined from interpretation of the in situ d.c. geoelectrical sounding data, as described in the text.

Fig. 6. (a) Salinity and temperature profiles measured on a sea-ice core from site 2 (Table 1). (b) Bulk sea-ice conductivity computed from the data in (a) using Archie's law, for different values of the exponent $m$. The horizontal dashed lines denote the horizontal $\left(\sigma_{\mathrm{h}}\right)$ and vertical $\left(\sigma_{\mathrm{v}}\right)$ conductivities determined from interpretation of the in situ d.c. geoelectrical sounding data.

coefficient of anisotropy of 0.5 for undeformed first-year Antarctic sea ice.

Figure 4 shows a consistent increase in the coefficient of anisotropy with decreasing sea-ice thickness, although it is difficult to say whether this is a real trend, given the limited number of measurements. Congelation (columnar) sea ice could be expected to show strong electrical anisotropy in comparison with frazil ice. Although no structural description was available for core $1 \mathrm{a}$, three cores taken from the same floe, and of almost identical thickness, contained an average of $75 \%$ congelation ice, with the uppermost sections of all cores being composed of frazil and snow ice. Core 2 was composed of $58 \%$ congelation ice, with the uppermost section of the core being composed of frazil and snow ice. Site 1 shows the strongest anisotropy, consistent with its higher content of congelation ice, although the difference in congelation ice contents seems too minor to explain the large difference in the coefficient of anisotropy at the two sites. The weaker anisotropy at site 2 could also be due to the relatively high temperature of the sea ice at this site. Table 1 suggests a general positive correlation between sea-ice temperature and the coefficient of anisotropy. This may imply an increase in the lateral interconnection between the brine cells with increasing temperature.

\section{DISCUSSION}

\section{Implications for airborne EM soundings of sea-ice thickness}

An arbitrarily oriented EM transmitter located on or above the surface of a layered earth will induce current flow only in the horizontal plane. EM measurements over undeformed, transversely isotropic sea ice are therefore sensitive only to the horizontal conductivity. This has been formally demonstrated for the case of a transversely isotropic half-space by Sinha (1968), but the result generalizes to the case of a multilayered earth (Yin and Fraser, 2004).

We have conducted a theoretical investigation of the sensitivity of the AWI HEM-Bird system to sea-ice conductivity. The AWI HEM-Bird is a two-frequency system which employs a horizontal coplanar transmitter-receiver geometry. Data are acquired at frequencies of 3680 and $112 \mathrm{kHz}$, with transmitter-receiver separations of 2.77 and $2.05 \mathrm{~m}$ respectively. At each frequency, the receiver measures the components of the secondary magnetic field both in-phase and out-of-phase with the primary magnetic field of the transmitter. The secondary fields are expressed as parts per million (ppm) of the primary field. The altitude of the system above the sea ice is monitored using a laser altimeter. A full 


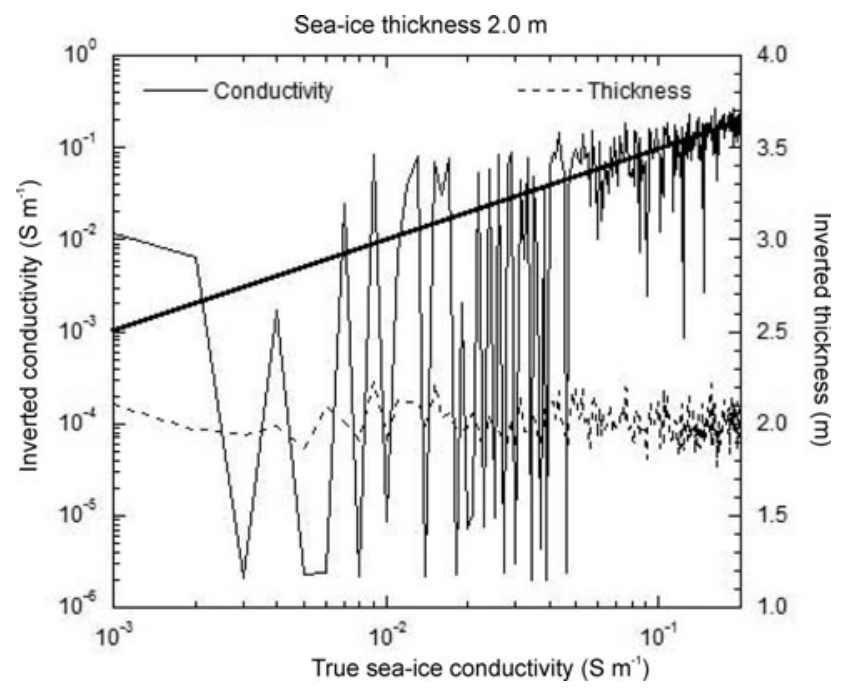

Fig. 7. Sea-ice conductivity and thickness recovered by inversion of noise-contaminated synthetic airborne EM data, for a suite of models in which the sea-ice thickness and sea-water conductivities were held fixed at $2 \mathrm{~m}$ and $2.77 \mathrm{~S} \mathrm{~m}^{-1}$ respectively, while the sea-ice conductivity varied between 0.001 and $0.2 \mathrm{~S} \mathrm{~m}^{-1}$. The heavy diagonal line denotes a $1: 1$ relationship between the true and inverted sea-ice conductivities. The height of the airborne EM system was assumed to be $15 \mathrm{~m}$ for all model calculations. A full description of the model parameters and noise levels is given in the text.

description of the system, and the practical techniques used to recover sea-ice thickness from the measured data, are given in Haas and others (2002) and Pfaffling and others (2004).

We have calculated the theoretical AWI HEM-Bird response of a suite of two-layer 1-D models, in which the sea-ice conductivity was varied while the sea-ice thickness and sea-water conductivity were held constant. The results of one such modelling exercise are shown in Figure 7. In this case, the two-layered model consisted of a $2 \mathrm{~m}$ thick layer of sea ice over sea water of conductivity $2.77 \mathrm{~S} \mathrm{~m}^{-1}$. The sea-ice conductivity used for the model calculations ranged from 0.001 to $0.2 \mathrm{~S} \mathrm{~m}^{-1}$ in increments of $0.001 \mathrm{~S} \mathrm{~m}^{-1}$. Random noise was added to the in-phase and out-of-phase components of the model response at each frequency. Noise levels were derived from data recorded during the 2003 field program. Noise was assumed to be Gaussian, with standard deviations of 6.38 and $5.81 \mathrm{ppm}$ for the in-phase and out-ofphase components at $3680 \mathrm{~Hz}$, and 9.24 and $13.42 \mathrm{ppm}$ for the in-phase and out-of-phase components at $112 \mathrm{kHz}$. The noise-contaminated data were then interpreted using a 1-D least-squares inversion program in order to attempt to simultaneously recover both sea-ice conductivity and thickness. The inversion process also assumed a two-layered model, in which the sea-ice thickness and conductivity were allowed to vary, while the sea-water conductivity was held fixed at $2.77 \mathrm{~S} \mathrm{~m}^{-1}$. This is similar to field situations, where the sea-water conductivity is usually known from independent measurements such as conductivity-temperaturedepth soundings. The starting model for the inversion assumed a sea-ice thickness of $4 \mathrm{~m}$, and conductivity of $0.1 \mathrm{~S} \mathrm{~m}^{-1}$. The sea-ice conductivity and thickness determined by inversion of the noisy synthetic data are shown in Figure 7. The true sea-ice thickness of $2.0 \mathrm{~m}$ is recovered quite well, with a maximum error of $12 \%$. However, the sea-ice conductivity is very poorly constrained, particularly for model conductivities of $<0.05 \mathrm{~S} \mathrm{~m}^{-1}$. The recovered conductivity exhibits variations of up to two orders of magnitude even for model sea-ice conductivities above $0.05 \mathrm{~S} \mathrm{~m}^{-1}$. Figure 7 shows that, given practical noise levels, the AWI HEM-Bird system is insensitive to the sea-ice conductivity, even over sea ice of thickness $2 \mathrm{~m}$.

We have found the sensitivity of the airborne EM response to sea-ice conductivity to be even lower over sea ice $<2 \mathrm{~m}$ thick. Our model calculations suggest that, given the practical noise limits of the AWI HEM-Bird system, the conductance of the sea ice ( $\sigma_{\mathrm{h}}$ times drilled thickness) must be around $0.25-0.4 \mathrm{~S}$ before the sea-ice conductivity can be recovered from the EM data with any degree of confidence. This is supported by further model calculations (not shown), which indicate that level sea ice of conductivity $0.05 \mathrm{~S} \mathrm{~m}^{-1}$ must be in excess of $5 \mathrm{~m}$ thick before the conductivity can be reliably recovered $(<10 \%$ error) from inversion of practical AWI HEM-Bird data.

The maximum sea-ice conductance determined from our in situ measurements was approximately $0.014 \mathrm{~S}$, including the contribution from the conductive near-surface layer (Table 1). The horizontal conductivities determined from our in situ d.c. sounding data are so low that the effects of sea-ice conductivity on AWI HEM-Bird data can generally be ignored over level sea ice in the East Antarctic, where the modal spring thickness is typically around $0.5 \mathrm{~m}$ (Worby and others, 1998). This may not be the case during the late summer, where high temperatures result in high brine volumes and a significantly increased bulk sea-ice conductivity (Haas, 1998).

\section{CONCLUSIONS}

Airborne EM measurements over transversely isotropic sea ice are sensitive only to the conductivity in the horizontal direction. Over level sea ice, it is possible to determine approximate horizontal and vertical conductivities from d.c. geoelectrical sounding data. Five Wenner-array geoelectrical soundings on level East Antarctic pack ice during spring 2003 have yielded average horizontal and vertical conductivities of 0.017 and $0.073 \mathrm{~S} \mathrm{~m}^{-1}$ respectively. These conductivities compare well with those from other in situ measurements reported in the literature. The widely used form of Archie's law (with exponent $m=1.75$ ) appears to significantly overestimate the horizontal conductivity of the sea ice.

High-frequency airborne EM data from the AWI HEMBird system have been shown to be insensitive to the electrical conductivity of undeformed East Antarctic sea ice, given the practical noise levels measured during the September 2003 field surveys. A much earlier field-based study of airborne EM measurements of sea-ice thickness (Kovacs and Holladay, 1990) reached a similar conclusion for Arctic sea ice. The insensitivity of the system to sea-ice conductivity was attributed to temperature-related drift affecting both the system electronics and transmitter frequency. Although the AWI HEM-Bird contains internal calibration coils which allow in-flight calibration factor adjustments during high-altitude drift correction of the data, further reductions in the noise levels (possibly coupled with an increased maximum transmitter frequency) are required before sea-ice conductivity measurements will be possible over the relatively thin sea ice typical of the East Antarctic. 


\section{ACKNOWLEDGEMENTS}

This research was supported by Australian Antarctic Science Advisory Committee grant 2381. We thank the officers and crew of RSV Aurora Australis for field support. K. Tateyama kindly provided the sea-ice core temperature data used to produce Figures 5 and 6 . We thank A. Munro for assistance with data acquisition and processing.

\section{REFERENCES}

Archie, G.E. 1942. The electrical resistivity $\log$ as an aid in determining some reservoir characteristics. Trans. Am. Inst. Min. Metal. Petrol. Eng., 146, 54-64.

Becker, A., D.C. Echert and G.B. White. 1992. Measurement of sea ice conductivity by electromagnetic induction. In Oceanic Engineering Society (US), ed. Oceans 92: Mastering the Oceans through Technology. Proceedings, 26-29 October 1992, Newport, Rhode Island, Vol. 2. Piscataway, NJ, Institute of Electrical and Electronic Engineers, 748-752.

Buckley, R.G., M.P. Staines and W.H. Robinson. 1986. In situ measurements of the resistivity of Antarctic sea ice. Cold Reg. Sci. Technol., 12(3), 285-290.

Cox, G.F.N. and W.F. Weeks. 1983. Equations for determining the gas and brine volumes in sea-ice samples. J. Glaciol., 29(102), 306-316.

Golden, K.M. 2001. Brine percolation and the transport properties of sea ice. Ann. Glaciol., 33, 28-36.

Haas, C. 1998. Evaluation of ship-based electromagnetic-inductive thickness measurements of summer sea-ice in the Bellingshausen and Amundsen Seas, Antarctica. Cold Reg. Sci. Technol., 27(1), 1-16.

Haas, C., S. Gerland, H. Eicken and H. Miller. 1997. Comparison of sea-ice thickness measurements under summer and winter conditions in the Arctic using a small electromagnetic induction device. Geophysics, 62(3), 749-757.

Haas, C., H. Edeler, M. Schürmann, J. Lobach and J.-P. Sengpiel. 2002. First operation of AWI HEM-bird for sea-ice thickness sounding. Proc. Jahrestag. Deut. Geophys. Gesell., 62, 36-58.

Kohnen, H. 1976. On the DC-resistivity of sea ice. Z. Gletscherkd. Glazialgeol., 11(2), 143-154.

Kovacs, A. 1996. Sea ice. Part 2. Estimating the full-scale tensile, flexural, and compressive strength of first-year sea ice. CRREL Rep. 96-11.

Kovacs, A. and J.S. Holladay. 1990. Sea-ice thickness measurement using a small airborne electromagnetic sounding system. Geophysics, 55(10), 1327-1337.

Kovacs, A., N.D. Valleau and J.S. Holladay. 1987. Airborne electromagnetic sounding of sea ice thickness and sub-ice bathymetry. Cold Reg. Sci. Technol., 14(3), 289-311.

Kovacs, A., J.S. Holladay and C.J. Bergeron, Jr. 1995. Footprint/ altitude ratio for helicopter electromagnetic sounding of sea-ice thickness: comparison of theoretical and field estimates. Geophysics, 60(2), 374-380.
Liu, G. and A. Becker. 1990. Two-dimensional mapping of seaice keels with airborne electromagnetics. Geophysics, 55(2), 239-248.

Maillet, R. 1947. The fundamental equations of electrical prospecting. Geophysics, 12(4), 529-556.

Morey, R.M., A. Kovacs and G.F.N. Cox. 1984. Electromagnetic properties of sea ice. Cold Reg. Sci. Technol., 9(1), 53-75.

Pfaffling, A., C. Haas and J.E. Reid. 2004. Empirical inversion of HEM data for sea ice thickness mapping. In Extended abstracts: 10th European meeting of environmental and engineering geophysics. Bremerhaven, Alfred Wegener Institute for Polar and Marine Research.

Prinsenberg, S.J., S. Holladay and J. Lee. 2002. Measuring ice thickness with EISFlow ${ }^{\mathrm{TM}}$, a fixed-mounted helicopter electromagnetic-laser system. In Chung, J.S., M. Sayed, M. Kashiwagi, T. Setoguchi and S.W. Hong, eds. Proceedings of the 12th International Offshore and Polar Engineering Conference, 2631 May 2002, Kitakyushu, Japan, Vol. 1. Cupertino, CA, International Society of Offshore and Polar Engineers, 737-740.

Sinha, A.K. 1968. Electromagnetic fields of an oscillating magnetic dipole over an anisotropic earth. Geophysics, 33(2), 346-353.

Stogryn, A. and G.J. Desargant. 1985. The dielectric properties of brine in sea ice at microwave frequencies. IEEE Trans. Antennas Propag., 33(5), 523-532.

Tateyama, K., S. Uto, K. Shirasawa and H. Enomoto. 2004. Electromagnetic-inductive measurements for the undeformed and deformed sea-ice and snow in the East Antarctic. In Chung, J.S., K. Izumiyama, M. Sayed and S.W. Hong, eds. Proceedings of the 14th International Offshore and Polar Engineering Conference, 23-28 May 2004, Toulon, France, Vol. I. Cupertino, CA, International Society of Offshore and Polar Engineers, 806-812.

Thyssen, F., H. Kohnen, M.V. Cowan and G.W. Timco. 1974. DC resistivity measurements on the sea ice near Point Inlet, N.W.T. (Baffin Island). Polarforschung, 44(2), 117-126.

Timco, G.W. 1979. An analysis of the in situ resistivity of sea ice in terms of its microstructure. J. Glaciol., 22(88), 461-471.

Watson, K.A. and R.D. Barker. 1999. Differentiating anisotropy and lateral effects using azimuthal resistivity offset Wenner soundings. Geophysics, 64(3), 739-745.

Weeks, W.F. and S.F. Ackley. 1986. The growth, structure, and properties of sea ice. In Untersteiner, N., ed. The geophysics of sea ice. New York, Plenum Press, 9-164.

Worby, A.P., R.A. Massom, I. Allison, V.I. Lytle and P. Heil. 1998. East Antarctic sea ice: a review of its structure, properties and drift. In Jeffries, M.O., ed. Antarctic sea ice: physical processes, interactions and variability. Washington, DC, American Geophysical Union, 41-67. (Antarctic Research Series 74.)

Worby, A.P., P.W. Griffin, V.I. Lytle and R.A. Massom. 1999. On the use of electromagnetic induction sounding to determine winter and spring sea ice thickness in the Antarctic. Cold Reg. Sci. Technol., 29(1), 49-58.

Yin, C. and D.C. Fraser. 2004. The effect of the electrical anisotropy on the response of helicopter-borne frequency-domain electromagnetic systems. Geophys. Prospect., 52(5), 399-416. 